\title{
Preparados homeopáticos e ambiente de cultivo na produção e rendimento de quercetina em carqueja [Baccharis trimera (Less) DC.]
}

\author{
CAPRA, R.S. ${ }^{1 * ;}$; GRATÃO, A.S. ${ }^{\prime ;}$ FREITAS. G.B. ${ }^{\prime ;}$ LEITE, M.N. ${ }^{2}$ \\ ${ }^{1}$ Departamento de Fitotecnia, Universidade Federal de Viçosa, UFV, Av. P.H. Rolfs, s/n, Viçosa, MG, CEP $36570-$ \\ 000, rscapra@hotmail.com.br;; ${ }^{*}$ Faculdade de Farmácia e Bioquímica, Universidade Federal de Juiz de Fora, \\ UFJF, Rua José Lourenço Kelmer, s/n, Juiz de Fora, MG, CEP 36036-330.
}

\begin{abstract}
RESUMO: A carqueja (Baccharis trimera) é uma espécie da família Asteraceae muito utilizada na medicina popular por apresentar várias atividades biológicas relacionadas à seus metabólitos secundários, entre eles os flavonoides. Este experimento teve como objetivo avaliar os efeitos de preparados homeopáticos e do ambiente de cultivo na produção e rendimento de flavonoides totais expressos em quercetina por plantas de carqueja. Foi adotado o esquema fatorial $6 \times 2$ no delineamento inteiramente casualisado, sendo 5 tratamentos homeopáticos: Silicea $\mathrm{CH} 6$, $\mathrm{CH} 12, \mathrm{CH} 30$, D7 e Equisetum D7 e controle (etanol 70\%) x 2 ambientes de cultivo: estufa e tela de sombreamento $50 \%$, com 4 repetições, totalizando 48 unidades experimentais. Os tratamentos homeopáticos foram aplicados na concentração de 25 gotas $/ 500 \mathrm{~mL}$ de água destilada usando borrifadores manuais. Cada planta recebeu $10 \mathrm{~mL}$ da solução por aplicação, via foliar. As aplicações foram realizadas sempre pela manha, três vezes por semana, em dias alternados, durante dois meses (27/07/2010 a 27/09/2010). A interação entre os fatores, assim como os fatores independentes foram comparados pelo teste Tukey a $5 \%$ de probabilidade. 0 efeito dos preparados homeopáticos e dos dois ambientes de cultivo em plantas de carqueja foi avaliado pelas variáveis: massa fresca (MFPA), massa seca (MSPA) e teor de quercetina (QCT) na parte aérea das plantas. As variáveis MFPA e QCT foram influenciadas pelos ambientes de cultivo, pelos preparados homeopáticos e pela interação entre os dois fatores. A variável MSPA foi influenciada apenas pela interação dos fatores. Plantas cultivadas em ambiente com $50 \%$ de sombreamento associadas à aplicação dos preparados homeopáti-cos Silicea $\mathrm{CH} 6 \mathrm{e}$ D7, apresentaram maior rendimento em querceti-na. Plantas cultivadas na estufa associadas à aplicação do Equisetum D7 apresentaram menor rendimento em quercetina.
\end{abstract}

Palavra-chave: Baccharis trimera, Silicea CH6, CH12, CH30, D7, Equisetum D7, sombreamento

\begin{abstract}
Homeopathic preparations and crop environments through production and yield of quercetin on carqueja plants [Baccharis trimera (Less) DC.]. The carqueja plant (Baccharis trimera) is a specie of the family Asteraceae widely used in folk medicine for presenting various biological activities, due to the high content of secondary metabolites, including flavonoids. The objective of this study was to evaluate the effect of homeopathic preparations and crop environments through production and yield of quercetina on carqueja plants. The experiment was a factorial scheme (6X2) on completely randomized design with 5 homeopathic treatments: Silicea CH6, CH12, CH30, D7 and Equisetum D7 e control (70\% ethanol) $\times 2$ crop environments: greenhouse and shade $50 \%$ and 4 replicates, totaling 48 experimental units. The treatments were applied at concentration of 25 drops $/ 500 \mathrm{~mL}$ of distilled water using hand sprayers. Each plant received $10 \mathrm{~mL}$ via leaves. The prepara-tions were sprayed always on mornings, three times a week on alternate days during two months (27/09/2010 to $27 / 11 / 2010)$. The interaction between the factors as well as the independents factors were compared by the Tukey test at $5 \%$ probability. The effect of homeopathic preparations and the two crop environments on carqueja plants were evaluated through the variables: fresh matter of aerial part (FMAP), dry matter of aerial part (DMAP) and flavonoids content (QCT). The variables FMAP and QCT were significantly influenced by the crop environments, the preparations and interaction between the two factors. The DMAP was only influenced by the interaction of the two factors. The $50 \%$ shade environment associated with Silicea $\mathrm{CH} 6$ or D7 increased yield of quercetin. The greenhouse environment associated with Equisetum D7 decreased yield of quercetin.
\end{abstract}

Keywords: Baccharis trimera, Silicea CH6, CH12, CH30, D7, Equisetum D7, shading.

Recebido para publicação em 23/04/2013

Aceito para publicação em 02/04/2014

10.1590/1983-084X/13 043

Rev. Bras. Pl. Med., Campinas, v.16, n.3, p.566-573, 2014. 


\section{INTRODUÇÃO}

A carqueja (Baccharis trimera (Less) $D C$.), espécie pertencente à família Astera-ceae, amplamente difundida em áreas tropicais, foi selecionada dentre as espécies prioritárias para a realização de estudos de conservação e manejo, no ecossistema da Mata Atlântica (EMBRAPA/ IBAMA, 2002).

Planta dióica, herbácea, perene e ereta com até $80 \mathrm{~cm}$ de altura, ocorre em todo o Brasil, desde o nível do mar até $2800 \mathrm{~m}$ de altitude. Desenvolvese em solos ácidos, pobres em nutrientes e matéria orgânica, nos campos nativos, em solos de textura média e bem drenados. Em solos férteis e úmidos desenvolvem-se de forma mais exuberante, sendo resistente à geadas. Propagase tanto vegetativamente como por sementes. A multiplicação vegetativa ocorre a partir de rizomas, formando touceiras.

Verdi et al. (2005) estudaram químicamente 120 espécies do gênero Baccharis, e de modo geral, os compostos em destaque foram os flavonoides, clerodanos e labda-nos, embora também se tenha observado com certa frequência a presença de kaura-nos, triterpenos, germacreno, ácidos cumá-ricos, tricotecenos, sesquiterpenos e fenil-propanoides. Os mesmos autores relataram que aproximadamente 30 espécies apresentaram atividade biológica, destacando-se os efeitos alelopáticos, antimicrobianos, citotóxi-cos e antiinflamatórios. Jarvis et al. (1991) e Zdero et al., (1991) caracterizaram o gênero Baccharis, pelo acúmulo de sesquiterpenos, diterpenos, triterpenos e flavonoides.

Na medicina popular a carqueja é usada como diurética, tônica, digestiva (Carneiro \& Fernandes, 1996), antirreumá-tica (Queiroga et al., 1996), analgésica, anti-inflamatória (Gené et al., 1992) e hepatopro-tetora. (Gianello et al., 2000).

Os flavonoides são metabolitos secundários pertencentes à classe dos poli-fenois, principais responsáveis pelo poder antioxidante dos vegetais. Alguns deles já foram isolados de $B$. trimera, como as: eupafolina, quercetina, luteolina, rutina, nepelina, apigenina, hispidulina, eriodictiol, eupatorina, genkwanina, cirsimaritina, cirsiliol, canferol, 5-OH-6,7,3,4-OMe flavona e 5,7,3,4-OH3-O-ramnosil-glicosil flavona (Verdi et al., 2005).

Aquercetina é o flavonoide mais amplamente distribuído no reino vegetal. Está presente em muitos alimentos, tais como: cebola, brócolis, maçã, chá-preto, frutas vermelhas e cítricas, entre outras ervas para fins medicinais. Como um proeminente flavonoide solúvel em água, a quercetina tem sido extensivamente estuda-da e compreensivelmente citada em artigos de revisão (Formiga \& Regelson, 1995; Graefe, Derendorf, Veite, 1999).
Além de sua alta capacidade anti-oxidante, a quercetina também apresenta propriedade antiviral, antiinflamatória, anti-proliferativa e antimicrobiana (Kawaii et al., 1999), assim como a maioria dos flavonoi-des, devido suas propriedades físico-químicas.

Estudos com espécies de uso medicinal têm evidenciado plasticidades fisiológicas, anatômicas e químicas em função das condições ambientais de cultivo (Letchano \& Gosselin, 1996). A anatomia das folhas, em particular, pode ser muito afetada pelas condições do meio, pois é o órgão vegetal de maior plasticidade, com grande capacidade de adaptação de suas estruturas internas, o que the confere amplo potencial de aclimatação (Björkman, 1981). O aumento da extensão do caule parece ser a tendência geral das plantas cultivadas à sombra, forma comum de se compensar a deficiência de luz, conforme constatações de Skuterud (1984) e Samarakoon et al. (1990a). O aumento em área foliar com o sombreamento é uma das adaptações que permite ao vegetal aumentar rapidamente a superfície fotossintetizante e assegurar um aproveitamento maior das baixas intensi-dades luminosas (Pedroso \& Varela, 1995).

Alguns estudos relatam a observação de teores de clorofilas mais elevados em folhas sombreadas em relação àquelas expostas ao sol, e uma razão clorofila $a / b$ maior para folhas de sol (Lei \& Lechowicz, 1998; Scalon et al., 2003). Zanella et al. (2006) observou uma tendência de aumento na concentração de clorofila total com o aumento do sombreamento. O mesmo autor, observou uma maior concentração de carotenoides totais nas plantas cultivas a pleno sol.

A luz atua de forma significativa e complexa no acúmulo e na variedade dos metabolitos secundários, uma vez que afeta direta ou indiretamente a produção de biomassa, a proporção de órgãos e as vias biossintéticas destes compostos (Oliveira et al., 2007). A luz é primordial para o crescimento das plantas, não só por fornecer energia para a fotossíntese, mas, também, por fornecer sinais que regulam seu desenvolvimento por meio de receptores de luz sensíveis a diferentes intensidades, qualidade espectral e estado de polarização. Dessa forma, modificações nos níveis de luminosidade ao qual uma espécie esta adaptada pode condicionar diferentes respostas fisiológicas em suas caracterís-ticas bioquímicas, anatômicas e de cresci-mento (Atroch et al., 2001).

Estudando B. trimera, Silva et al., (2006b) relataram a influência dos níveis de radiação (100, 60,50 e $20 \%$ ) no crescimento da planta e na qualidade do óleo essencial.

Dentre os fatores climáticos, o foto-período, 
a temperatura, o estresse hídrico e a intensidade de radiação solar podem determinar a qualidade medicinal das espé-cies cultivadas para esse fim, objetivando uma maior quantidade do princípio ativo desejado.

Além da manipulação do ambiente, como a utilização de estufas e tela de sombreamentos, a homeopatia é outra ferramenta que vem sendo utilizada com sucesso na produção vegetal, principalmente no cultivo de plantas medicinais. (Andrade \& Casali, 2011).

A homeopatia tem como base a experimentação das preparações altamente diluídas e sucussionadas. Todos os fenômenos da homeopatia são repetitíveis, previsíveis, quantificáveis, descritíveis e tem relação causaefeito, assim como, base teórica explicativa (Casali et al., 2006). As bases conceituais da homeopatia são coerentes não apenas com as mais recentes teorias físicas de compreensão do Universo (SILVA, 1999) como é coerente com os princípios que norteiam a sustentável produção orgânica e ecológica de alimentos (Casali, 2004).

A ciência da homeopatia aplicada às plantas tem suporte bibliográfico, metodoló-gico e teórico; tem dispositivo legal desde 1999, sendo recomendada na Instrução Normativa $N^{\circ} 7$, sobre a produção orgânica no Brasil (BRASIL, 1999). A homeopatia se insere em qualquer modelo agrícola, alternativo ou convencional, por disponibili-zar conhecimento das "Leis de Cura" (equilíbrio) dos seres vivos, viabilizando o equilíbrio natural (Casali et al., 2006).

São incontáveis os benefícios do uso da homeopatia no cultivo das plantas, pro-porcionando aumento da imunidade vegetal, sementes mais vigorosas, variação na pro-dução e rendimento de princípios ativos (fitoquímicos com propriedades medicinais), alteração de padrão energético, adaptação a condições adversas e controle de pragas e doenças (Andrade, 2012). As plantas medici-nais são boas experimentadoras dos preparados homeopáticos. As respostas em plantas são sinalizadas no metabolismo secundário o qual está diretamente relacio-nado à defesa e as interações ambientais. Assim, as plantas medicinais são úteis à pesquisa básica confirmando em plantas a ação da homeopatia sob o mecanismo de defesa (Andrade \& Casali, 2011).

Segundo Casali et al. (2009) o preparado homeopático Silicea é indicado às plantas estioladas, às variedades susceptí-veis ao míldio, plantas com dificuldades de assimilação de nutrientes, raquíticas, plantas estressadas abioticamente pelo déficit hídrico, temperaturas baixas, resíduo de herbici-da e bioticamente, infectadas por fungos, bactérias, pragas e outras interrupções no crescimento.
Embora existam poucos trabalhos utilizando o preparado homeopático Equise-tum (cavalinha) em vegetais, essa planta foi homeopatizada e utilizada por conter uma alta concentração de sílica em suas estruturas.

Várias pesquisas vêm sendo feitas, principalmente no Brasil, para elucidar as atividades biológicas e os metabólitos secun-dários envolvidos nos processos fisiológicos e ecofisiológicos em plantas medicinais. A carqueja, muito utilizada na medicina popular, apresenta imenso potencial científico, uma vez que é planta rústica, perene, fácil propagação, possui várias classes de metabólitos secundários, com diversas atividades biológicas, podendo ser objeto de estudo multidisciplinar com potencial não apenas com fins medicinais, mas também como testadora de preparados homeopáticos.

Este trabalho teve o objetivo de avaliar os efeitos de preparados homeo-páticos, à base de sílica e Equisetum, e de ambientes de cultivo, estufa e tela de sombreamento $50 \%$, na produção e rendi-mento de quercetina em plantas de carqueja (B. trimera).

\section{MATERIAL E MÉTODO}

O experimento foi desenvolvido no Setor de Agroecologia do Departamento de Fitotecnia da Universidade Federal de Viço-sa, no município de Viçosa-MG, situado a $20^{\circ} 45^{\prime}$ de latitude sul e $42^{\circ} 51^{\prime}$ de longitude oeste, na altitude de $651 \mathrm{~m}$. A região apre-senta inverno frio e seco e verão quente e chuvoso, com temperatura média de $19,4^{\circ} \mathrm{C}$ e precipitação média de $1221 \mathrm{~mm}^{2} \mathrm{ano}^{-1}$. As condições climáticas durante a condução do experimento (27/09 a 27/11/2010), no município de Viçosa/MG, se encontram na Tabela 1.

A produção das mudas de carqueja foi realizada pelo processo de estaquia. Estacas com aproximadamente $10 \mathrm{~cm}$ de comprimento foram feitas de uma única matriz coletada no Sítio Contena, no município de Viçosa-MG, em 27 de março de 2010. A exsicata do material botânico encontra-se depositada no Herbário da UFV, número de registro VIC 33.093. Para a produção das mudas, as estacas foram colocadas em tubetes plásticos contendo composto orgânico como substrato e mantidas em casa de vegetação equipada com sistema de nebulização até o enraíza-mento. Quando as mudas atingiram $15 \mathrm{~cm}$ de altura foram transplantadas em sacolas plásticas pretas perfuradas com capacidade de 1,5 litros, utilizando como substrato a mistura de terra de subsolo e esterco bovino curtido na proporção de $3: 1(\mathrm{v} / \mathrm{v})+$ termofos-fato yorin e sulfato de potássio, nas doses de $5,0 \mathrm{~kg} \mathrm{e} \mathrm{0,5} \mathrm{kg}_{\text {por } \mathrm{m}^{3}}$ de mistura, respectivamente. 
Tabela 1. Médias mensais das temperaturas mínimas, médias e máximas, precipitação, umidade relativa do ar e brilho solar, no período de 27/09 a 27/11/2010, em Viçosa/MG (Fonte: Boletim Meteorológico 2010 Departamento de Engenharia Agrícola, UFV)

\begin{tabular}{cllllll}
\hline \multirow{2}{*}{$\begin{array}{c}\text { Variáveis } \\
\text { Climáticas }\end{array}$} & \multicolumn{2}{l}{ Temperatura $\left({ }^{\circ} \mathrm{C}\right)$} & & Chuva & U.R. & Brilho Solar \\
\cline { 2 - 7 } & Mín & Méd & Máx & $(\mathrm{mm})$ & $(\%)$ & $(\mathrm{hs})$ \\
\hline Setembro * & 17.5 & 20.5 & 25.0 & 23 & 81 & 3.2 \\
Outubro & 17.0 & 20.5 & 26.5 & 147 & 75 & 115 \\
Novembro ** & 18.0 & 21.0 & 26.0 & 393 & 84 & 76 \\
\hline
\end{tabular}

* $=$ do dia $27 / 09$ a 30/09/2010

${ }^{* *}=$ do dia $01 / 11$ a $27 / 11 / 2010$.

Após o transplantio, as mudas foram colocadas em dois ambientes: estufa e tela de sombreamento $50 \%$, onde cada uma recebeu $50 \mathrm{~g}$ de composto orgânico peneira-do e foram submetidas aos preparados homeopáticos.

O experimento foi instalado no esquema fatorial $6 \times 2$ no delineamento inteira-mente casualizado, sendo o primeiro fator representado por cinco preparados homeo-páticos Sil $\mathrm{CH} 6$, Sil $\mathrm{CH} 12$, Sil CH30 e Sil D7 e Equi D7 e testemunha (etanol $70 \%$ ) e o segundo fator pelos dois ambientes de cultivo (estufa e tela de sombreamento $50 \%$ ). Foram utilizadas quatro repetições com duas mudas/ repetição, totalizando 48 unidades experimentais.

Os preparados homeopáticos foram adquiridos em farmácia de manipulação idônea no município de Viçosa-MG. Os tratamentos foram aplicados em duplo-cego, via foliar, com auxílio de borrifadores manu-ais de $500 \mathrm{~mL}$, três vezes por semana, em dias alternados, sempre pela manhã, duran-te dois meses (27/09/2010 à 27/11/2010). Os preparados homeopáticos, assim como o controle (etanol $70 \%$ ), foram diluídos na concentração de 25 gotas $/ 500 \mathrm{~mL}$ de água destilada, sendo aplicado 10 $\mathrm{mL}$ por muda por aplicação.

Durante o experimento, as mudas foram irrigadas diariamente, até atingir a capacidade de campo, e as plantas espontâ-neas eliminadas quando necessário. Não houve problema com pragas e doenças.

Aos 60 dias, após o início dos tratamentos, as plantas foram colhidas, a parte aérea destacada da radicular na região do colo, e submetidas à avaliação da massa fresca (MFPA), seca (MSPA) e teor de flavonoide total em quercetina (QCT) na parte aérea (alas caulinares).

A parte aérea fresca das plantas foi seca em estufa com circulação forçada de ar a $30^{\circ} \mathrm{C}$ por 96 horas, e, em seguida, acondi-cionadas em sacos de papel e armazenadas até as análises químicas (AGOSTINI et al., 2005). Por ocasião das análises químicas, a parte aérea seca foi triturada em liquidifi- cador industrial e passadas no tamis de tamanho apropriado, obtendo amostras com partículas entre 0,5 e 1,0 mm (FARMACO-PÉIA BRASILEIRA IV).

$O$ procedimento de doseamento de flavonoide na matéria seca vegetal foi feito de acordo com recomendações da Farmaco-peia Brasileira IV. A porcentagem de flavo-noide foi calculada em relação à quercetina por espectrofotometria/UV.

A pesagem da parte aérea das plantas foi realizada no Laboratório de Agroecologia do Departamento de Fitotec-nia-UFV, utilizando balança de precisão. A análise química de flavonoide foi realizada no Departamento de Farmácia da Universi-dade Federal de Juiz de Fora.

Na determinação dos teores de flavo-noide, a massa de 0,4 gramas da droga vegetal triturada (partículas de 0,5-1,0 $\mathrm{mm}$ ) foi aquecida à fervura moderada sob refluxo durante 30 minutos com 20 $\mathrm{mL}$ de acetona e $2 \mathrm{~mL}$ de ácido clorídrico. $\mathrm{O}$ extrato vegetal foi filtrado com algodão para um balão volumétrico de $100 \mathrm{~mL}$. O resíduo da droga vegetal com o algodão voltou para o refluxo com mais 20 $\mathrm{mL}$ de acetona por 10 minutos em fervura moderada por mais duas vezes visando garantir a extração total dos flavo-noides. Os extratos foram filtrados com algodão e adicionados ao balão volumétrico e completado com acetona até atingir $100 \mathrm{~mL}$ (extrato acetônico).

No funil de separação foram adicionados $20 \mathrm{~mL}$ da solução filtrada com $20 \mathrm{~mL}$ de água destilada e $15 \mathrm{~mL}$ de acetato de etila. Após a separação da fase aquosa (F.A), a fase orgânica (F.O.) foi recolhida em um balão volumétrico de 50 $\mathrm{mL}$. A F.A. restante foi adicionada a $10 \mathrm{~mL}$ de acetato de etila por mais duas vezes e separada da F.O. Após a reunião das F.O. de acetato de etila, foram realizadas 2 lavagem com porções de $50 \mathrm{~mL}$ de água destilada para purificação do extrato orgânico. A F.O. foi completada com acetato de etila no balão volumétrico de $50 \mathrm{~mL}$ (solução mãe - S.M.).

Para a leitura da absorbância no espectrofotômetro/UV, $10 \mathrm{~mL}$ da S.M. foram 
adicionados a $1 \mathrm{~mL}$ de solução de cloreto de alumínio e o volume foi completado com solução metanólica a $5 \%(\mathrm{v} / \mathrm{v})$ de ácido acético em balão volumétrico de $25 \mathrm{~mL}$.

Após 30 minutos, foi lida a absor-bância das amostras a $425 \mathrm{~nm}$ utilizando a mesma solução sem a adição do cloreto de alumínio como branco. O teor de flavonoide total em quercetina (\%) foi calculado por meio da equação:

$$
\% \text { flavonoides }=\frac{A \times \text { F.D. }}{500 \times \mathrm{M} \times(100-P d)}
$$

Onde:

A = absorbância da amostra a $425 \mathrm{~nm}$;

F.D $=$ fator de diluição $=62.500$

$500=$ absorção específica da quercetina

$\mathrm{M}=$ massa da amostra em gramas;

$\mathrm{Pd}=$ determinação da porcentagem de água presente na amostra.

Os resultados obtidos foram submetidos à análise de variância $(p<0,05)$ e as médias comparadas pelo teste de Tukey ao nível de $5 \%$ de probabilidade através do software SAEG-UFV (SAEG, 2001).

\section{RESULTADO E DISCUSSÃO}

Nas variáveis MFPA e QCT houve efeito significativo $(p<0,05)$ de ambas as fontes de variação e sua interação. A MSPA foi influenciada $(p<0,05)$ apenas pela interação entre ambiente e os preparados homeopáticos (TABELA 2).

$\mathrm{Na}$ Tabela 3 encontram-se as médias da massa da parte aérea fresca (MFPA).

Verifica-se que plantas cultivadas sob tela de sombreamento $50 \%$ apresentaram maior acúmulo de MFPA, exceto plantas que receberam o preparado homeopático Silicea $\mathrm{CH} 30$ cujo valor de MFPA foi semelhante ao de plantas cultivadas em estufa. No ambien-te sombreado, os preparados Silicea $\mathrm{CH} 30$ e Equisetum D7 provocaram menor acúmulo de massa fresca da parte aérea das plantas. Os demais preparados não alteraram esta característica das plantas, neste ambiente de cultivo.

No ambiente da estufa, o uso dos preparados Silicea CH12, D7 e Equisetum D7 resultou em menor acúmulo de MFPA pelas plantas, comparado ao tratamento testemunha (controle). Contudo, não se observou diferenças significativas entre os tratamentos homeopáticos.

Em relação ao acúmulo de massa seca da parte aérea (MSPA), característica muito importante do ponto de vista comer-cial, verifica-se que os preparados Silicea $\mathrm{CH} 6, \mathrm{CH} 12, \mathrm{CH} 30$ e D7 provocaram valores de MSPA semelhantes nos dois ambientes de cultivo (Tabela 4).

No controle (testemunha) houve maior acúmulo de MSPA, quando cultivadas em estufa. Resultados semelhantes foram obtidos por Sales et al. (2009) trabalhando com Hortelã-do-campo (Hyptis marrubioides Epl.), Souza et al. (2007) com Alecrim-pimenta (Lippia sidoides Cham.), Auken\& Bush (1990) estudando Baccharis neglecta e Castrillo et al. (2005) com plantas de sambacaita [Hyptis pectinata(L.) Poit.], manjericão (Ocimum basilicumL.), alecrim (Rosmarinus officinalis L.) e sálvia (Salvia officinalis L.).Todos os autores observaram maior acúmulo de fitomassa seca nas folhas em cultivo sob maiores níveis de irradiância.

Nas plantas que receberam o prepa-rado Equisetum D7 houve maior acúmulo de MSPA, quando cultivadas sob tela de sombreamento $50 \%$.

No ambiente sombreado, a aplicação de preparados homeopáticos não influenciou o acúmulo de MSPA pelas plantas. Na estufa, plantas que receberam os prepa-rados Silicea $\mathrm{CH} 12$ e Equisetum D7 apre-sentaram menores valores de MSPA em relação ao tratamento testemunha (controle), porém não diferiram dos demais

Tabela 2 . Resumo da análise de variância das variáveis massa fresca (MFPA), massa seca (MSPA) e teor de quercetina (QCT) da parte aérea de plantas de carqueja submetidas a tratamentos homeopáticos em dois ambientes de cultivo

\begin{tabular}{llllc}
\hline \multirow{2}{*}{ FV } & \multirow{2}{*}{ GL } & \multicolumn{3}{c}{ Quadrados Médios } \\
\cline { 3 - 5 } & & MFPA & \multicolumn{1}{c}{ MSPA } & Q \\
\hline Amb (A) & 1 & $244,848^{*}$ & $0,004^{\text {ns }}$ & $0,143^{*}$ \\
Preps (P) & 5 & $12,481^{*}$ & $0,326^{\text {ns }}$ & $0,015^{*}$ \\
AXP & 5 & $15,852^{*}$ & $0,805^{*}$ & $0,012^{*}$ \\
Resíduo & 36 & 14,675 & 0,224 & 0,002 \\
\hline CV \% & 9,24 & 9,01 & 9,07 \\
\hline * - F significativo a 5\% de probabilidade \\
ns - F não significativo.
\end{tabular}

Rev. Bras. Pl. Med., Campinas, v.16, n.3, p.566-573, 2014. 
Tabela 3. Médias da massa fresca da parte aérea $(\mathrm{g})$ de plantas de carqueja submetidas a tratamentos homeopáticos, em dois ambientes de cultivo

\begin{tabular}{ccc}
\hline Preparados Homeopáticos & Estufa & Tela de sombreamento $50 \%$ \\
\hline Controle & $13,10 \mathrm{Ab}$ & $15,79 \mathrm{Aa}$ \\
Silicea CH6 & $10,86 \mathrm{ABb}$ & $16,94 \mathrm{Aa}$ \\
Silicea CH12 & $9,51 \mathrm{Bb}$ & $16,55 \mathrm{Aa}$ \\
Silicea CH30 & $11,91 \mathrm{ABa}$ & $12,34 \mathrm{Ba}$ \\
Silicea D7 & $10,15 \mathrm{Bb}$ & $17,71 \mathrm{Aa}$ \\
Equisetum D7 & $9,52 \mathrm{Bb}$ & $12,82 \mathrm{Ba}$ \\
\hline
\end{tabular}

Médias seguidas pelas mesmas letras maiúsculas na coluna e minúsculas na linha não diferem entre si pelo teste Tukey a 5\% de probabilidade.

Tabela 4. Médias da massa seca da parte aérea $(\mathrm{g})$ de plantas de carqueja submetidas a tratamentos homeopáticos, em dois ambientes de cultivo

\begin{tabular}{llcc}
\hline Preparados Homeopáticos & \multicolumn{2}{l}{ Estufa } & Tela de sombreamento $50 \%$ \\
\hline Controle & 6,11 & $\mathrm{Aa}$ & $5,04 \mathrm{Ab}$ \\
Silicea CH6 & $5,42 \mathrm{ABa}$ & $5,03 \mathrm{Aa}$ \\
Silicea CH12 & $4,87 \quad \mathrm{Ba}$ & $5,23 \mathrm{Aa}$ \\
Silicea CH30 & $5,11 \mathrm{ABa}$ & $5,42 \mathrm{Aa}$ \\
Silicea D7 & $5,28 \mathrm{ABa}$ & $5,49 \mathrm{Aa}$ \\
Equisetum D7 & $4,70 \quad \mathrm{Bb}$ & $5,39 \mathrm{Aa}$
\end{tabular}

Médias seguidas pelas mesmas letras maiúsculas na coluna e minúsculas na linha não diferem entre si pelo teste Tukey a 5\% de probabilidade.

Tabela 5. Médias dos teores de flavonoides totais em Quercetina (\%) da parte aérea seca de plantas de carqueja, submetidas aos tratamentos homeopáticos, em dois ambientes de cultivo

\begin{tabular}{|c|c|c|}
\hline Preparados Homeopáticos & Estufa & Tela de sombreamento $\mathbf{5 0} \%$ \\
\hline Controle & $0,50 \mathrm{ABCa}$ & $0,56 \mathrm{Ba}$ \\
\hline Silicea $\mathrm{CH} 6$ & 0,56 & $0,67 \mathrm{Aa}$ \\
\hline Silicea CH12 & $0,44 \mathrm{BCDb}$ & $0,57 \mathrm{Ba}$ \\
\hline Silicea $\mathrm{CH} 30$ & $0,54 \quad \mathrm{ABa}$ & $0,53 \mathrm{Ba}$ \\
\hline Silicea D7 & $\mathrm{CDb}$ & $0,63 \mathrm{ABa}$ \\
\hline Equisetum D7 & 0,40 & $0,58 \mathrm{ABa}$ \\
\hline
\end{tabular}

Médias seguidas pelas mesmas letras maiúsculas na coluna e minúsculas na linha não diferem entre si pelo teste Tukey a 5\% de probabilidade.

tratamentos homeopáticos.

A luz atua de forma significativa e complexa no acúmulo e na variedade dos metabolitos secundários, uma vez que afeta direta ou indiretamente a produção de biomassa, a proporção de órgãos e as vias biossintéticas destes compostos (Oliveira et al., 2007).

Além do ambiente de cultivo, o acúmulo de quercetina pelas plantas de carqueja também foi influenciado pelos tratamentos homeopáticos.

Verifica-se que plantas cultivadas sob tela de sombreamento $50 \%$ apresentaram teores de quercetina iguais ou superiores a plantas cultivadas em estufa. No ambiente sombreado, a Silicea $\mathrm{CH} 6$ foi o preparado homeopático que mais aumentou o teor de quercetina na parte aérea das plantas, sendo superior aos preparados Silicea $\mathrm{CH} 12$ e CH30 e ao controle. Os preparados Silicea D7 e Equisetum D7 não diferiram dos demais tratamentos (Tabela 5)

$\mathrm{Na}$ estufa, plantas que receberam o preparado Silicea $\mathrm{CH} 6$ apresentaram os maiores teores de quercetina na MPAS, contudo, este tratamento não diferiu estatisticamente dos tratamentos controle e Silicea CH30. Já o uso do preparado Equisetum D7 resultou na diminuição significativa no teor de quercetina na parte aérea das plantas, quando comparado ao tratamento controle, e não diferiu dos tratamentos Silicea $\mathrm{CH} 12$ 
e Silicea D7.

De modo geral, observa-se que na estufa, o uso de preparados homeopáticos resultou na redução da massa seca da parte aérea das plantas. Com isso, apesar de alguns preparados homeopáticos terem aumentado ligeiramente os teores de quercetina na MSPA, a produção total de quercetina por plantas tratadas com os diferentes preparados foi igual ou inferior à produção das plantas que não receberam tratamento homeopático.

No ambiente sombreado, plantas tratadas com preparados homeopáticos não diferiram estatisticamente entre si na produ-ção de MSPA. Porém, plantas tratadas com os preparados Silicea CH6 e Silicea D7 apresentaram maiores teores de quercetina na MSPA, resultando em maiores produções de quercetina por planta, superando o tratamento controle em $21 \%$ e $25 \%$, respectivamente.

Os resultados obtidos estão de acordo com Casali (2004), Castro (2001) e Andrade (2000) ao recomendar as plantas medicinais como testadoras de preparados homeopá-ticos, uma vez que esses preparados dina-mizados atuam de forma significante nas plantas como um todo, mas principalmente no metabolismo secundário, estimulando o mecanismo de defesa e a adaptação eco-fisiológica, visando o equilíbrio e o bem estar vegetal.

Embora não houve diferença estatísti-ca entre os controles, no ambiente sombrea-do a produção de quercetina foi superior em $12 \%$ quando comparado com o ambiente de estufa.

O preparado homeopático Silicea $\mathrm{CH} 6$ melhorou o desempenho de plantas de carqueja cultivadas em ambiente sombreado em relação à produção de quercetina em $20 \%$. O mesmo preparado homeopático associado ao sombreamento $50 \%$ foi superior em $34 \%$ e $20 \%$ quando comparado com o controle do ambiente de estufa e com o mesmo tratamento homeopático na estufa, respectivamente.

A utilização dos preparados homeopá-ticos Silicea CH12 e Silicea D7, embora não diferiram estatisticamente dos controles dos respectivos ambientes, quando associados ao ambiente sombreado foram superiores em $30 \%$ e $47 \%$ com relação ao ambiente de estufa, respectivamente.

O preparado homeopático Equisetum D7 associado ao ambiente de estufa não é recomendado para produção de quercetina, sendo $20 \%$ e $29 \%$ inferiores ao controle do ambiente de estufa e ao controle do ambiente sombreado, respectivamente.

Já no ambiente sombreado, o preparado Equisetum D7 aumentou em $45 \%$ a produção de quercetina quando comparado com o mesmo tratamento homeopático no ambiente de estufa.

\section{REFERÊNCIA}

AGOSTINI, F. et al. Estudo do óleo essencial de algumas espécies do gênero Baccharis (Asteraceae) do sul do Brasil. Revista Brasileira de Farmacognosia, v.15, n.3, p.215-220, 2005.

ANDRADE, F.M.C. Homeopatias no crescimento e na produção de cumarina em chambá (Justicia pectoralis Jacq.). Revista Brasileira Plantas Medicinais, Botucatu, v.14, especial, p.154-158, 2012.

ANDRADE, F.M.C.; CASALI, V.W.D. Homeopatia, agroecologia e sustentabilida-de. Revista Brasileira de Agroecologia. V.6, n.1, p.49-56, 2011.

ATROCH, E.M.A.C. et al. Crescimento, teor de clorofilas, distribuição de biomassa e características anatômicas de plantas jovens de Bauhinia forficata Link submetidas à diferentes condições de sombreamento. Ciência e Agrotecnologia, v.25, n.4, p.853-862. 2001.

AUKEN, O.W.V.; BUSH, J.K. Influence of light levels, soil nutrients, and competition on seedling growth of Baccharis neglecta (Asteraceae). Bulletin of the Torrey Botanical Club, v.117, n.4, p.438-444. 1990.

BJORKMAN, O. Responses to different quantum flux densities.In: Lange, O.et al. (Eds.). Physiological plant ecology: responses to the physical environment. New York: Springer-Verlang, 1981. p.57-60.

BRASIL. Instrução normativa $n^{\circ} 07$, de 17 de maio de 1999. Dispõe sobre normas para produção de produtos orgânicos vegetais e animais. Diário Oficial [da República Federativa do Brasil], Brasília, v.99, n.94, p. 11-14, 19 maio 1999. Seção 1.

BRASIL. FARMACOPÉIA BRASILEIRA. 4ed.v.2, f.4, São Paulo: Atheneu, 1996. p.58-62.

CARNEIRO, M.A.A.; FERNANDES, G.W. Herbivoria. Ciência Hoje. v.20, n.118, p.35-39, 1996.

CASALI, V.W.D.; ANDRADE, F.M.C.; DUARTE, E.C. Acologia de altas diluições. Viçosa: DFT/UFV, 2009. 600p.

CASALI, V.W.D. et al. Homeopatia: bases e princípios. Viçosa: DFT/UFV, 2006. 149p.

CASALI, V.W.D. Utilização da homeopatia em vegetais. In: SEMINÁRIO BRASILEIRO sobre HOMEOPATIA na AGROPECUÁRIA ORGÂNICA. 1., 2004, Toledo. Anais ... Viçosa: DFT/UFV, 2004, p.89-117.

CASTRILLO, M. et al. Specific leaf mass, fresh: dry weight ratio, sugar and protein contends in species of Lamiaceae from different light environments. Revista de Biologia Tropical, v.53, p.23-28, 2005.

CASTRO, D.M. Produção de óleo essencial e campo eletromagnético de capim-Limão (Cymbopogon citratus) tratado com soluções homeopáticas. In: SEMINÁRIO BRASILEIRO SOBRE HOMEOPATIANAAGROPECUÁRIA ORGÂNICA, 2., 2001. Espírito Santo do Pinhal. Anais... Viçosa: DFT/UFV, 2001. p.165-174.

EMBRAPA; IBAMA. Estratégia para conservação e manejo dos recursos genéticos de plantas medicinais e aromá-ticas: resultados da primeira reuni-ão técnica. Brasília: EMBRAPA/IBAMA, 2002. $184 p$.

FORMICA, J. V.; REGELSON, W. Review of the biology of quercetin and related bioflavonoids. Food Chemistry Toxicology, v.33, n.12, p.1061-1080, 1995. 
GENE, R.M.; CARTARANA, C.; ADZET, T. Antiinflammatory effects of aqueous extract of three species of the genus Baccharis. Planta Medica. v.58, n.6, p.565-566, 1992.

GIANELLO, J.C. et al. Medicamentos herbá-rios en el centro-oeste argentino. II. "Carquejas": control de calidad de lãs drogas oficiales y sustituyentes. Acta Farmaceutica Bonaerense, v.19, n.2, p.99-103, 2000.

GRAEFE, E.U.; DERENDORF, H.; VEIT, M. Pharmacokinetics and bioavailability of the flavonolquercetin in humans. International Journal Clinical Pharmacology Therapeu-tics, v.37, n.5, p.219-233, 1999.

JARVIS, B.B. et al. Trichotecenos mycoto-xins from Brazilian Baccharis species. Phytochemistry, v.30, p.789-797, 1991.

KAWAII, S. et al. Anti-proliferative activity of flavonoids and ceveral câncer cell lines. Bioscience Biotechnology and Bioche-mistry. v.63, n.5, p.896-899, 1999.

LEI, T.T.; LECHOWICZ, M.J. Diverse responses of maple saplings to forest light regimes. London: Annals of Botany, v.82, n.1, 1998, p.9-19.

LETCHANO, W.; GOSSELIN, A. Transpira-tion essential oil gland, epicuticular wax, and morphology of Thymus vulgaris are influenced by light intensity and water supply. Journal Horticultural Science, v.71, 1996, p.123-134, 1996.

OLIVEIRA, F.S. Atividade antiviral da quercetina sobre alguns vírus de importância veterinária. 2007. 138p. Dissertação (Mestrado - Área de Concentra-ção em Bioquímica Agrícola) - Departamento de Bioquímica Agrícola, Universidade Fede-ral de Viçosa, Viçosa.

PEDROSO, S.G.; VARELA, V.P. Efeito do sombreamento no crescimento de mudas de sumaúma (Ceiba pentandra (L.) Gaertn). Revista Brasileira de Sementes, v.17, n.1, p.47-51, 1995.

QUEIROGA, M.L.; FERRACINE, V.F. Three new oxigenated cardinanes from Baccharis species. Phytochemistry, v.42, n.4, p.1097-1103, 1996.

SAEG. Sistema para análises estatísticas: versão 5.0. Viçosa: Fundação Artur Bernardes, 2001.

SALES, J.F. et al. Acúmulo de massa, teor foliar de nutrientes e rendimento de óleo essencial de hortelãdo-campo (Hyptis marrubioides EPL.) cultivado sob adubação orgânica. Bioscience Journal, v.25, n.1, p.60-68, 2009.

SAMARAKOON, S.P.; WILSON, J.R., SHELTON, H.M. Growth, morphology and nutritive quality of shaded Stenotaphrum secundatum, Axonopus compressus and Pennisetum clandestinum. Journal Agricultural Science, v.114, n.2, p.161-169, 1990.

SCALON, S.P.Q. et al. Crescimento inicial de mudas de Bombacopsis glabra (Pasq.) A. Robyns sob condição de sombreamento. Revista Árvore, v.27, n.6, p.753758, 2003.

SILVA, F.G. Influência do nível de irradiância no crescimento da planta, rendimento e composição do óleo essencial em carqueja. Ciência e Agrotecnologia, v.30, n.1, p.52-57, 2006.

SILVA, W. R. G. Análise parcial do Organon face as necessidades do $3^{\circ}$ milênio. In: BRUNINI, C. (Coord.). Homeopatia, princípios e doutrina II. São Paulo: Typus, p. 39-51, 1999.

SKUTERUD, R. Growth of Elymus repens(L.) Gould and Agrostis gigantean Roth. at different light intensities. Weed Research, v.24, n.1,p.51-57, 1984.

SOUZA, M.F. et al. Influência do sombrea-mento na produção de fitomassa e óleo essencial em alecrimpimenta (Lippia sidoides Cham.) Revista Brasileira de Biociências, v.5, supl.2, p.108-110, 2007.

VERDI, L.G.; BRIGHENTE, I.M.C.; PIZZO-LATTI, M.G. Gênero Baccharis (Asteraceae): aspectos químicos, econômicos e biológicos. Química Nova, v.28, n.1, p.85-94, 2005.

VITHOULKAS, G. Homeopatia: ciência e cura.São Paulo: Editora Cultrix, 1980. 463p.

ZANELLA, F. et al. Formação de mudas de maracujazeiro amarelo sob níveis de sombreamento em Ji-Paraná/ RO. Ciência agrotecnologia., v.30, n.5, p.880-884, 2006.

ZDERO, C.; BOHLMANN, F.E.; NIEMEYER, H.M.. An unusual dimeric sesquiterpene and other constituents from Chilean Baccharis species. Phytochemistry, v.30, p.1597-1601, 1991. 